\title{
ČTYŘUZLOVÝ KONEČNÝ PRVEK ZALOŽENÝ NA HELLINGER-REISSNER VARIAČNÍM PRINCIPU
}

\author{
HELLINGER-REISSNER VARIATIONAL PRINCIPLE BASED \\ QUADRILATERAL FINITE ELEMENT
}

Monika Středulová*, ${ }^{*}$ Jan Eliášs ${ }^{1}$

"stredulova.m@fce.vutbr.cz

${ }^{1}$ Vysoké učení technické v Brně, Fakulta stavební, Veveří 331/95, 60200 Brno-střed

\begin{abstract}
Abstrakt
Metoda konečných prvků je bezpochyby jedna z nejrozšířenějších metod pro řešení úloh mechaniky pevných těles. Nicméně, jedná se o metodu aproximační a její výsledky jsou závislé na definici prvku použitého pro výpočet. Nejjednodušší prvky s jedním primárním polem často trpí takzvaným „zamykáním“, tedy přilišnou tuhostí při ohybovém namáhání nebo pokud je těleso tvořeno nestlačitelným materiálem. $\mathrm{V}$ takovém př́ípadě je alternativou použití prvku o více neznámých polích. Článek představuje jeden z prvků o dvou neznámých polích formulovaný na základě Hellinger-Reissner variačního principu a na př́kladech porovnává jeho robustnost $\mathrm{s}$ ostatními metodami, které byly v minulosti použity pro odstranění zamykání. Úlohy jsou řešeny v rámci lineární elasticity.
\end{abstract}

\section{Klíčová slova}

Metoda konečných prvků, lineární pružnost, Hellinger-Reissner variační princip, zamykání

\section{Abstract}

The Finite Element Method is without a doubt one of the most prominent tools in solving the equations governing mechanics of solids. It is an approximative method and, as such, its performance largely depends on the definition of the finite element used in a computation. The simplest elements, based on one primary field, tend to suffer from "locking", that is excessive stiffness when an element is subjected to bending or the material is nearing the limit of incompressibility. One of the alternatives is the use of an element based on multiple primary fields. The present article aims to describe one such element (based on mixed-field Hellinger-Reissner variational principle) and analyze its robustness in comparison to other methods which were used in the past to mitigate locking. The analysis will be done in the framework of linear elastostatics.

\section{Key words}

Finite Element Method, linear elasticity, Hellinger-Reissner variational principle, locking

\section{INTRODUCTION}

The Finite Element Method is one of the most widely used methods to approximate differential equations describing the behavior of solid materials. In its most basic form, the elements which are used for computation are based on the principle of virtual work. Such formulations have one primary field of variables (usually displacements or stresses) and for that are also called irreducible formulations. The simplest elements used in the framework are then elements using linear shape functions, mapping the displacements between nodes linearly. The appeal of such formulation in the design process lies primarily in straightforward implementation and low computational demands. In two-dimensional idealization, an example of such an element is the Q4 element (displacement-based bilinear quadrilateral) [1].

Although being adequate in many cases, there are situations in which the irreducible formulation and linear shape functions are not sufficient in providing appropriate results [2], [3]. The lack of robustness is commonly referred to as locking and is demonstrated by excessive stiffness of the structure, resulting in largely underestimated or zero displacements. It is prominent in two particular situations: (i) when a body undergoes bending-dominated deformation or (ii) when the material is nearly incompressible [3]. 
The results may be typically improved by refinement of the mesh, however, such intervention results inevitably in larger computational demands. The possibility of using coarse mesh, without any potentially dangerous bias to the solution in terms of underestimated results, has thus been sought after and alternatives were suggested in the literature throughout the years. One such alternative is the use of an element based on mixed-field variational principles [4]. Such element then solves in the computational procedure more than one primary field, providing the element with more degrees of freedom and offering more precise results while only minimally increasing computational costs.

The present article aims to analyze one such mixed-field element, based on the Hellinger-Reissner variational principle, developed by Pian and Sumihara [5] (PS element). In the first part of the article, a short description of locking along with an overview of the alternative methods is provided, which were used to overcome the phenomena. It is followed by a brief description of the mixed-field element. Finally, a validation procedure of the implemented element is described, followed by an analysis of an example that is prone to both forms of locking and thus is commonly used to evaluate the performance of alternative finite elements (FE). The same example was previously used in the literature to evaluate the performance of other elements, which also offers the possibility of assessing the PS element performance in a wider context.

\section{THEORETICAL BACKGROUND}

The following section discusses the origin of locking behavior in elements based on the irreducible formulation and possible remedies. Subsequently, the Pian-Sumihara (PS) element is introduced with emphasis on the matrix form of equations which allows straightforward implementation.

\section{Locking behavior}

According to Babuška and Suri [6], locking is in mathematical terms a parameter-dependent problem. When a parameter value approaches a certain limit, locking occurs. The meaning of the parameter is physical, with clear interpretation. Two distinct locking situations are recognized based on the parameter meaning: (i) shear locking occurs when beam depth or a membrane thickness $t \rightarrow 0$ and (ii) volumetric locking occurs when Poisson's ratio $v \rightarrow 0.5$.

In the first case, spurious transverse shear strains develop, rendering the element incapable of representing bending dominated or other shear-free behavior [7]. The bilinear quadrilateral may serve as an example. When subjected to bending the element is not capable of approximating the exact displacements and the wrong shape of deformation is compensated by spurious stresses. As a result, the element is stiffer and the results are underestimated. The situation is described in Fig. 1 [8].

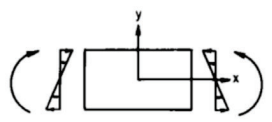

a)

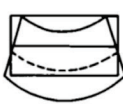

b)

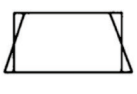

c)

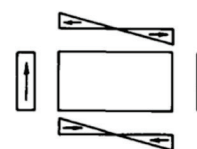

d)

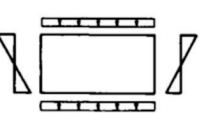

Fig. 1 Shear locking of the bilinear quadrilateral. a) geometry and normal stresses, b) exact deformation, c) approximation by the bilinear quadrilateral, d) spurious shear stresses, e) spurious stresses in y direction.

Figure is taken from [8].

In contrast, volumetric locking occurs when the material is nearing the limit of incompressibility, that is when the volume of an element is defined as constant throughout deformation and no volumetric strain occurs. Mathematically, it is a constraint to the vector of displacements $\mathbf{u}$, which limits the space of admissible solutions to the subspace of incompressible solutions [4] as:

$$
\boldsymbol{\nabla} \cdot \mathbf{u}=\mathbf{0}
$$

The goal in developing mathematical formulations to solve the problems is then to formulate a robust method, such that the stability of the method and, subsequently, the results as well, are independent of the parameter [6].

The behavior is prominent when using a coarse mesh and will eventually disappear using finer mesh $(h$ refinement). However, such "brute force" as described by Babuška in [6], may not always be available given the ever-present limit to the computational resources at hand and so alternative approaches are sought-after.

One possibility is to increase the polynomial order of shape functions, called $p$-refinement [9]. One of the appeals of the FEM is the straightforward implementation of such an approach, however, increasing 
the polynomial order inevitably increases the number of degrees of freedom (DOFs), leading to a computationally more expensive procedure.

Selective reduced integration (SRI) has been successfully used in the past. It is based on the notion that one may divide the constitutive matrix $\mathbf{E}$ into multiple parts, each describing a different part of a deformation [4]. Subsequently, the stiffness matrix integral may be also divided and reduced integration may be used to the parameter-dependent part. In the case of shear locking, the parameter-dependent part describes shear stiffness, while in the case of volumetric locking it is the deviatoric term.

Alternatively, the displacement field may be enhanced by internal degrees of freedom, which are incompatible between elements and allow better approximation of displacements [8]. The elements are referred to as incompatible modes elements.

Last but possibly the largest group of methods is based on mixed-field variational principles. The common foundation encompasses multiple methods. One example is the B-bar method, which extends the B matrix (a displacement-strain) operator by exchanging terms related to the parameter-dependent part of deformation to its approximation based on a mixed-field principle [4]. Enhanced strain elements are commonly based on the three-field $\mathrm{Hu}$-Washizu variational principle [10], incorporating enhanced strains that may be eliminated at an element level [11]. The use of mixed field variational principles also allows approximating multiple unknown fields independently. Commonly, such a procedure is applied to two primary fields. In such a case the second field acts as a Lagrange multiplier, incorporating a constraint. One example of such an approach is the u-p hybrid element, which is popular for incompressibility problems [1]. It uses displacements as the internal unknown field and pressure in an element as the external unknown field, which acts as a constraint ensuring incompressibility. A detailed account of the element formulation may be found in [1].

The mixed-field Pian-Sumihara element [5] which is central to the present article uses two unknown internal fields as primary fields: stresses and displacements. The element is described in detail in the subsequent paragraph.

\section{Pian-Sumihara element}

The Pian-Sumihara (PS) element [5] is a four-node quadrilateral element that uses stress and displacement fields as primary unknown fields, based on the Hellinger-Reissner variational principle. The principle will not be derived in the present article but may be found for example in [1] or [12]. The relationships between variables of the model may be conveniently described by Tonti's diagram (Fig. 2). In the figure, a solid line represents a strong form of an equation to be satisfied in every point of a domain, while a dashed line stands for a weak link, which is to be satisfied in an integral sense. The diagram contains two strain variables, $\varepsilon^{u}$ produced by displacements and $\boldsymbol{\varepsilon}^{\sigma}$ produced by independent stresses. The difference between the two is equal to zero, and the relationship is expressed by an equation in a weak form, summed over the volume of an element.

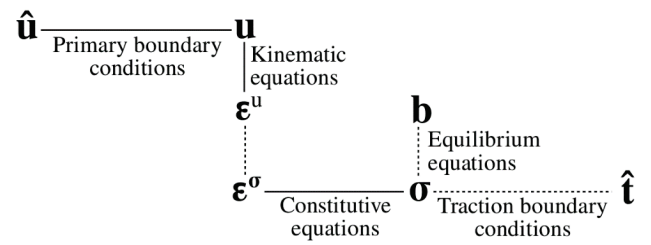

Fig. 2 Tonti's diagram of the model.

As in the case of any FE, there are unknown parameters to the state of an element. The stresses in the PS element $\boldsymbol{\sigma}$ are approximated by five independent parameters collected in vector $\boldsymbol{\alpha}=\left\{\begin{array}{lllll}\boldsymbol{\alpha}_{1} & \boldsymbol{\alpha}_{2} & \boldsymbol{\alpha}_{3} & \boldsymbol{\alpha}_{4} & \boldsymbol{\alpha}_{5}\end{array}\right\}^{\mathrm{T}}$. The displacement field contains eight degrees of freedom, two per node, collected in vector

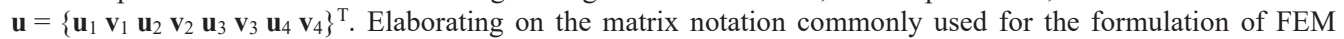
(see for example [1]), primary boundary conditions are given by prescribed displacements $\hat{\mathbf{u}}=\mathbf{u}$ on surface $S_{\mathrm{u}}$. Displacements are linearly interpolated in an element using linear shape functions associated in matrix $\mathbf{H}$. The functions are $\mathrm{C}^{0}$ continuous, returning displacements continuous over elements [1]. The kinematic equation is given by $\boldsymbol{\varepsilon}^{\mathfrak{u}}=\mathbf{B u}$, where $\mathbf{B}$ is the matrix of shape functions derivatives and $\boldsymbol{\varepsilon}_{\mathrm{u}}$ are the strains of displacements. Strains produced by independent stresses are calculated by inverting the constitutive equation as $\boldsymbol{\varepsilon}^{\sigma}=\mathbf{E}^{-1} \boldsymbol{\sigma}$, where matrix $\mathbf{E}$ is the constitutive matrix. Stresses are expressed as $\boldsymbol{\sigma}=\mathbf{J}_{(0,0)} \boldsymbol{\alpha} \mathbf{J}_{(0,0)}{ }^{\mathrm{T}}$, alternatively with the help of matrix $\mathbf{G}$ describing the transformation as $\boldsymbol{\sigma}=\mathbf{G} \boldsymbol{\alpha}$.

$$
\left[\begin{array}{ll}
\sigma_{x x} & \tau_{x y} \\
\tau_{y x} & \sigma_{y y}
\end{array}\right]=\left[\begin{array}{ll}
J_{11} & J_{12} \\
J_{21} & J_{22}
\end{array}\right]\left[\begin{array}{cc}
\alpha_{1}+\eta \alpha_{4} & \alpha_{3} \\
\alpha_{3} & \alpha_{2}+\xi \alpha_{5}
\end{array}\right]\left[\begin{array}{cc}
J_{11} & J_{12} \\
J_{21} & J_{22}
\end{array}\right]^{\mathrm{T}}
$$


Unknown parameters to the stress state $\alpha$ approximate effective stresses at the element level. Normal stresses have a constant and linear term while shear stress is constant. The effective stresses are transformed to cartesian (global) coordinates with the help of a Jacobi matrix, evaluated at the center of an element $\mathrm{J}(0,0)$. Stresses do not fulfill continuity requirement [5]. Given traction and body forces are used to obtain a vector of the right side ( Eq. (4)).

Substituting the matrix form of the equations given in the previous paragraph into the variational form of HR functional [10], one obtains the following system of linear equations:

$$
\left[\begin{array}{cc}
\mathbf{K}_{11} & \mathbf{K}_{12} \\
\mathbf{K}_{21} & 0
\end{array}\right]\left\{\begin{array}{l}
\boldsymbol{\alpha} \\
\mathbf{u}
\end{array}\right\}=\left\{\begin{array}{l}
\mathbf{0} \\
\mathbf{f}
\end{array}\right\}
$$

whose entries are evaluated as separate volume and surface integrals.

$$
\mathbf{K}_{11}=\int_{V} \mathbf{G}^{\mathrm{T}} \mathbf{E}^{-\mathbf{1}} \mathbf{G} d V, \quad \mathbf{K}_{\mathbf{1 2}}=\int_{V} \mathbf{G}^{\mathrm{T}} \mathbf{B} d V=\mathbf{K}_{\mathbf{2 1}}^{T}, \quad \mathbf{f}=\int_{S_{t}} \mathbf{H}^{\mathrm{T}} \hat{\mathbf{t}} d S_{t}+\int_{V} \mathbf{H}^{\mathrm{T}} \mathbf{B} d V
$$

The system of equations Eq. (3) allows for the separation of the two vectors of unknown parameters with the use of static condensation [13]. The first expression is used to obtain the global stiffness matrix and to compute the (continuous) displacements, while the stress parameters are calculated separately at an element level. Effectively, only $\mathbf{u}$ degrees of freedom are solved at the global level:

$$
-\mathbf{K}_{12}^{T} \mathbf{K}_{11}^{-1} \mathbf{K}_{12} \mathbf{u}=\mathbf{f}, \quad \mathbf{K}_{12}^{T} \boldsymbol{\alpha}=\mathbf{f}
$$

\section{VALIDATION}

To analyze the performance of the Pian-Sumihara element, it was implemented in an FEM algorithm. A necessary step is the validation of the implementation via a patch test. It provides both validation of a formulation and verification of its implementation by solving a problem with a known solution and comparing the results.

Based on [1], a simple rectangular structure of width $b$ and depth $h$ was chosen to be tested in uniaxial tension by prescribed displacements $u_{\mathrm{x}=0}=0$ and non-zero displacement $\mathrm{u}_{\mathrm{x}=\mathrm{b}}$ and to be solved as a plane stress problem. The structure is discretized into a mesh of 10 by 10 elements and two cases are tested using the implemented PS element: (i) regular mesh and (ii) randomly disturbed mesh. The exact values of internal nodal displacements and displacements obtained by the algorithm are compared for both cases. The exact nodal displacements are given as:

$$
u_{n}=\frac{u_{x=b}}{b} x_{\mathrm{n}}, \quad u_{\mathrm{n}}=-\frac{v v_{x=b}}{h} y_{n}
$$

A relative error $e_{\mathrm{r}}$ between the exact solution $\mathbf{u}$ and the computed solution $\overline{\mathbf{u}}$ is calculated separately for each direction (subscript $\mathrm{n}$ denotes individual node, $N$ denotes the number of degrees of freedom, $i$ labels either $u$ or $v$ ):

$$
e_{r, i}=\sqrt{\frac{\sum_{n=1}^{N}\left(u_{i, n}-\bar{u}_{i, n}\right)}{\sum_{n=1}^{N} u_{i, n}^{2}}}
$$

Tab. 1 Results obtained by the patch test.

\begin{tabular}{ccc}
\hline & $\begin{array}{c}\text { regular } \\
\text { mesh }\end{array}$ & $\begin{array}{c}\text { disturbed } \\
\text { mesh }\end{array}$ \\
\hline$e_{\mathrm{r}, \mathrm{u}}$ & $2,391^{-15}$ & $6,473^{-15}$ \\
$e_{\mathrm{r}, \mathrm{v}}$ & $1,4^{-13}$ & $6,149^{-14}$ \\
\hline
\end{tabular}

The results show excellent agreement between the exact solution and the one obtained using the PS element. The errors are due to limited machine precision.

\section{ANALYSIS OF ELEMENT BEHAVIOR}

Cook's membrane, a test case chosen from literature, was used in the past to test the performance of elements specifically developed for situations prone to locking. Its previous use allows the comparison to other elements, namely: (i) SRI element with reduced integration of volumetric term [4], QM6 incompatible element developed 
by Simo \& Rafai [11], assumed strain element Qi5 developed by César de Sá \& Natal [4] and B-bar element as described in [14]. Furthermore, standard bilinear quadrilateral Q4 [1] is also included to illustrate the locking behavior.

Cook's membrane is a classical problem of a clamped tapered panel loaded by traction, commonly solved by both non-linear and linear solvers [4]. The latter will be used in the present analysis. The problem combines bending and near incompressible material of $v=0.4999999$. Further material parameters (in consistent system of units) are: modulus of elasticity $E=240.565$, thickness $t=1$ and traction $q=100$. Vertical displacement of the top right corner (node $\mathrm{A}[48,60]$ ) is recorded and its convergence with increasing the number of elements is analyzed. The following discretizations were tested: 1 element, 2 elements per side (4 elements), 4 elements per side ( 8 elements), 8 elements per side (64 elements), 16 elements per side ( 256 elements) and 32 elements per side (1024 elements). Both the geometry and results of the analysis are shown below.
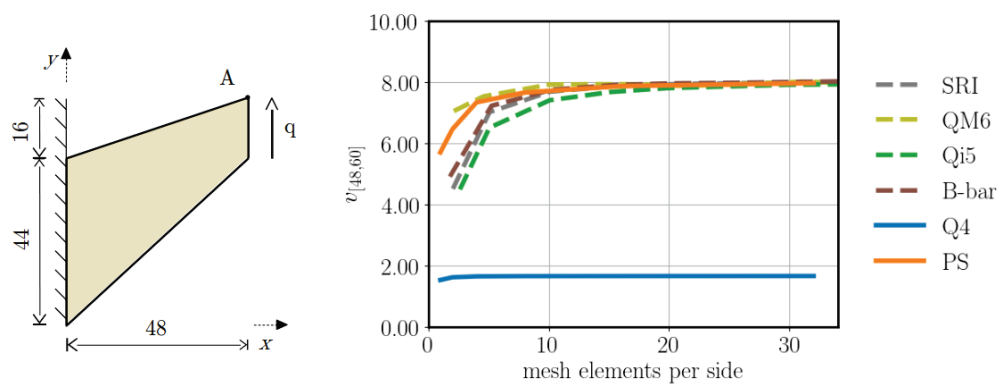

Fig. 3 Geometry of the Cook's membrane (left) and results of the convergence analysis (right).

The resulting graph shows convergence analysis of the tested PS element as well as other elements described in literature. Additionally, the results obtained by the standard bilinear element (Q4) are shown. As expected, the results obtained by the Q4 element are affected by locking. The element shows much higher stiffness and displacements of about $80 \%$ lower compared to the other elements are obtained. Contrary to the theory of $h$ refinement, the element does not show improvement for the increased number of elements.

As expected, the PS element shows excellent results and largely exceeds the performance of the Q4 element even in the case of the coarsest mesh (geometry discretized into 1 element). Clearly, the performance of the element is neither affected by the incompressibility, nor by bending. In the context of other elements, the PS element also shows good results. A difference is visible especially in the first two tested cases, that is a mesh of 1 element and 4 elements, where the PS element shows better results than the other elements, except for the QM6 incompatible modes element. Subsequently, the results for the higher number of elements are similar and no clear distinction between performances of individual elements can be observed as the results converge to the same, presumably exact solution.

\section{CONCLUSIONS}

The article aimed to describe the mixed-field quadrilateral finite element developed by Pian \& Sumihara [5] as a remedy to both volumetric and shear locking, i.e. phenomena demonstrated by excessive stiffness of affected elements.

Firstly the origin and the mechanisms of both shear and volumetric locking were described. It was demonstrated that the simplest irreducible linear elements are mostly affected, because of their inability to approximate the shape of a deformation that is required to fulfill the constraint. An overview of methods previously used in literature to avoid the phenomena at low computational costs has been given, providing a context of the Pian-Sumihara element. Subsequently, the element itself was described.

To analyze the performance of the element, it was implemented into a FEM script, which was validated via patch test. The test compared solutions obtained by the algorithm with the exact solution for a simple plane stress problem in uniaxial tension. The resulting errors between the two were at the level of machine precision.

The behavior of the element was observed on an example commonly used to test locking tendencies of elements: the Cook's membrane. The problem combines both the nearly incompressible material and bending and as it is a common benchmark problem, results obtained by other elements are available in the literature, offering wider comparison. 
In the convergence analysis, the performance of the PS element was comparable or even superior to other elements, developed with the same motivation. Only the incompatible modes element developed by Simo and Rafai [11] showed better performance in the Cook's membrane problem.

The bilinear quadrilateral element was included in the analysis to demonstrate the locking behavior. Interestingly, the element showed constant results. It was not possible to test a mesh finer than 1024 elements due to limited computational power available, however, the recorded trend suggests no improvement vis-à-vis mesh refinement, supporting the necessity of elements dedicated to locking prone situations.

However, the present analysis was limited to the framework of linear elasticity, assuming small displacements, small rotations, and linear stress-strain relationship, which restricts the interpretation of results to very specific problems. The element showed excellent results, however, the analysis is limited by the assumptions of linear elasticity, restricting the interpretation of the results.

\section{References}

[1] O. C. Zienkiewicz, R. L. Taylor, and J. Z. Zhu, The finite element method: its basis and fundamentals, Seventh edition. Amsterdam: Elsevier, 2013.

[2] I. Babuška and M. Suri, "On Locking and Robustness in the Finite Element Method", SIAM Journal on Numerical Analysis, vol. 29, no. 5, pp. 1261-1293, 1992.

[3] R. J. Alves de Sousa, R. M. Natal Jorge, R. A. Fontes Valente, and J. M. A. César de Sá, “A new volumetric and shear locking-free 3D enhanced strain element”, Engineering Computations, vol. 20, no. 7, pp. 896-925, 2003.

[4] J. M. César De Sá and R. M. Natal Jorge, "New enhanced strain elements for incompressible problems", International Journal for Numerical Methods in Engineering, vol. 44, no. 2, pp. 229-248, 1999.

[5] T. H. H. Pian and K. Sumihara, "Rational approach for assumed stress finite elements," International Journal for Numerical Methods in Engineering, vol. 20, no. 9, pp. 1685-1695, sep 1984.

[6] I. Babuška and M. Suri, "On Locking and Robustness in the Finite Element Method," SIAM Journal on Numerical Analysis, vol. 29, no. 5, pp. 1261-1293, 1992.

[7] L. Yunhua, "Explanation and elimination of shear locking and membrane locking with field consistence approach", Computer Methods in Applied Mechanics and Engineering, vol. 162, no. 1-4, pp. 249-269, 1998.

[8] E. Wilson, R. Taylor, W. Doherty, and J. Ghaboussi, Incompatible Displacement Models. ACADEMIC PRESS, INC., 1973.

[9] I. Babuška, "The p and h-p Versions of the Finite Element Method: The State of theArt," pp. 199-239, 1988.

[10] K. Washizu, Variational Methods in Elasticity \& Plasticity, 1968.

[11] J. C. Simo and M. S. Rifai, "A class of mixed assumed strain methods and the method of incompatible modes, “International Journal for Numerical Methods in Engineering , vol. 29, no. 8, pp. 1595-1638, 1990.

[12] O. C. Zienkiewicz, "Displacement and equilibrium models in the finite element method by B. Fraeijs de Veubeke, Chapter 9, Pages 145-197 of Stress Analysis, Edited by O. C. Zienkiewicz and G. S. Holister, Published by John Wiley \& Sons, 1965," International Journal for Numerical Methods in Engineering, vol. 52, no. 3, pp. 287-342, 2001.

[13] R. J. Guyan, "Reduction of stiffness and mass matrices,“ AIAA Journal, vol. 3, no. 2, p. $380,1965$.

[14] T. J. R. Hughes, The Finite Element Method: Linear Static and Dynamic Finite Element Analysis. Mineola (New York): Dover Publications, 2000. 